\title{
What we talk about when we talk about pediatric suffering
}

\author{
Tyler Tate ${ }^{1}$
}

Accepted: 5 December 2020 / Published online: 5 January 2021

(c) The Author(s), under exclusive licence to Springer Nature B.V. part of Springer Nature 2021

\begin{abstract}
In this paper I aim to show why pediatric suffering must be understood as a judgment or evaluation, rather than a mental state. To accomplish this task, first I analyze the various ways that the label of suffering is used in pediatric practice. Out of this analysis emerge what I call the twin poles of pediatric suffering. At one pole sits the belief that infants and children with severe cognitive impairment cannot suffer because they are nonverbal or lack subjective life experience. At the other pole exists the idea that once child suffering reaches some threshold it is ethical to eliminate the sufferer. Concerningly, at both poles, any particular child vanishes from view. Second, in an attempt to identify a theory of suffering inclusive of children, I examine two prominent so-called experiential accounts of suffering. I find them both wanting on account of their absurd entailments and their flawed assumptions regarding the subjective experiences of people who cannot communicate expressively. Finally, I extend arguments found in Alastair MacIntyre's Dependent Rational Animals to argue that child suffering can be understood only as a set of absences-absences of conditions such as love, warmth, and freedom from pain. An evaluation of these absences reveals the exquisite dependency of children. It also discloses why pediatric suffering is necessarily a social and political event. Unlike adults, children will never be either the authors or the mitigators of their own suffering. Rather, children must rely wholly on others in order to resist suffering, grow, and flourish.
\end{abstract}

Keywords Suffering · Quality of life · Disability · Pediatric ethics · Withholding/ withdrawing treatment

After trying to read all I could get my hands on concerning the meaning of suffering, I am convinced that never has there been a word used with such an uncritical assumption that everyone knows what they are talking about.

—Stanley Hauerwas, Suffering Presence, 1986 [1, p. 29]

Tyler Tate

tatety@ohsu.edu

1 Oregon Health and Science University, Portland, OR, USA 


\section{Introduction}

Suffering is a knotty topic. This is true for several reasons. For one, it is a difficult concept to pin down. As soon as you think you have defined the idea, for instance as "a deep sense of unpleasantness or distress," a counterexample arises (e.g., "Brazilian rainforests suffered greatly in 2019 due to unchecked fires and political inertia"). Another reason is the enormity of what is at stake. Suffering demands action, and as both utilitarians and humanitarians have trenchantly advocated over the past two centuries, if you can suffer you deserve rights, sympathy, and a position in the moral universe. Suffering is not to be taken lightly.

The suffering of children presents its own unique challenges. What does it mean to say that a child is suffering? Does it simply mean that the child is experiencing pain, fear, or anxiety? Or does it mean something more, something about the child's subjective mental, existential, or spiritual life? The suffering of infants and children with significant cognitive impairment, like baby Esther, is even harder to understand. ${ }^{1}$ What does it mean to say that Esther is suffering? Where exactly is Esther's suffering located? And granting that Esther can suffer, does confirmation of her suffering lie in the judgment of clinicians or parents? Or does its confirmation require more objective data, like vital sign changes or physical exam findings? Perhaps most importantly, if Esther can indeed suffer, how should clinicians respond?

In this paper I will explore these questions. I will do so in three stages. First, I will examine two customary applications of the label of suffering in pediatric practice. Second, I will analyze so-called psychological or experiential theories of suffering and show why they fail to either capture or clarify the experience of child suffering, especially for newborns or profoundly impaired children like Esther. Finally, drawing from Alasdair MacIntyre's naturalized virtue theory, I will advance my own view of pediatric suffering which comports with both ordinary language and basic pediatric developmental theory.

\section{Pediatric suffering: mirage or scandal?}

Suffering is an important concept for pediatric ethics, especially when evaluating the lives of children with severe disability. ${ }^{2}$ Yet as Erica Salter has recently noted, conceptualizations of pediatric suffering are typically either meager or obscure [4]. While there are many reasons for this, I suspect one is that, as a heuristic, it is easy to locate pediatric suffering at one of two poles. At one pole, it is believed that to warrant the full stamp of legitimacy, the experience of suffering must be more than witnessed; it must also be articulated. Adults can suffer. Newborns cannot. Newborns may feel pain, hunger, or nausea, but not suffering. This stance treats pediatric suffering as a mirage. At the other pole, the possibility of suffering in pediatric

\footnotetext{
1 The case of baby Esther is laid out in my introduction to this Theoretical Medicine and Bioethics special issue on pediatric suffering [2].

2 I flesh out this claim in [2, 3].
} 
patients who cannot use language is viewed with great anxiety. The concern that a child could be suffering but unable to describe her experience or ask for help leads some to believe that death is a preferable alternative for such patients. This stance treats pediatric suffering as a scandal. As I have suggested elsewhere [3], these tropes are recurrent and pervasive in pediatric medicine.

The suffering-as-mirage trope is advanced forcefully by Eric Cassell, who believes that infants and children with significant cognitive impairment cannot suffer: "In order to suffer a person must be aware of the past and the future and be able to assign meaning. This is why animals may suffer but very young infants not suffer. They can have pain, even terrible pain, but not suffer" [5, p. 221]. In this way, suffering in such individuals is like a mirage: it only seems to exist. Cassell's criteria for suffering are stringent; to suffer one must undergo an injury or threat to personhood, and personhood in turn requires language, agency, a sense of time, a vision of the future, and an ability to attribute meaning to events. For newborns and children with serious cognitive impairments, these are criteria that cannot be met.

In Cassell's view, Oliver Sacks offers a paradigmatic description of genuine suffering in his characterization of life while hospitalized for a devastating leg injury. Sacks observes that as an immobile patient, "one is no longer a free agent; one no longer has rights; one is no longer in the world at large. It is strictly analogous to becoming a prisoner, and humiliatingly reminiscent of one's first day at school. One is no longer a person-one is now an inmate" [6, p. 27]. Here language provides the medium through which Sacks's suffering is unveiled to the world, and as Cassell would see it, insofar as Sacks realizes that his injury means something bad for himnamely, that he is "incarcerated" within the hospital and may never again be able to express his cherished identity as an outdoorsman and transcontinental explorer-his experience can be recognized as something more than bare pain, anxiety, or fear. Save for those being particularly tendentious, most would agree that Sacks is undergoing something distinct from any negative experience available to, say, a lobster, a racoon, or a chimpanzee. Certainly Sacks is suffering! Yet this kind of disclosure of private distress, the public and justifying sine qua non of suffering, is not available to the very young.

This kind of "mirage logic" is influential within pediatrics. ${ }^{3}$ For example, within the hospital, parents of children with profound disabilities are often granted broad decision-making authority over the application of life-sustaining interventions for their child. This liberal allowance for parental decision-making, even when it runs counter to advice from medical providers, is interwoven with the belief that children with profound cognitive impairments cannot suffer. In other words, because these children are viewed as incapable of suffering, their parents are granted nearly unlimited control over the application of potentially unadvisable interventions. ${ }^{4}$

\footnotetext{
3 An explicit formulation of the mirage logic might be as follows: (1) suffering is "real" only insofar as it is linguistically represented (or the experience of suffering and the coherent expression of suffering are one and the same), and therefore (2) beings who cannot express suffering cannot suffer.

4 An example of this mode of thinking is seen when a hospital continues to treat a brain-dead patient, or a patient dying on extracorporeal membrane oxygenation who is heavily sedated (and therefore supposedly unable to suffer), because parents request that the medical staff not let their child die. This suffering-
} 
At the other pole, a suffering-as-scandal trope surfaces in settings where pediatric suffering is taken as a deeply serious reality, giving rise to different questions regarding life and death. This contrasting reality-at its extreme-is exemplified in the Netherlands, where the controversial Groningen protocol allows for euthanasia of severely ill newborns in select cases. Killing such children is permitted up to the age of one in "the presence of hopeless and unbearable suffering" [9]. The attitude of the protocol is that suffering is a scandal-a behavior or an event that people think is morally or legally wrong and that causes public feelings of shock or anger. Scandals warrant suppression or erasure. Within the Groningen protocol, suffering is scandalized, and conditions are laid out under which the merciful act may be to eliminate suffering by eliminating the sufferer. Although neonatal euthanasia is currently confined to one European country, scholars have argued that this practice may be the natural and logical extension of self-determination laws around dying, such as the Death with Dignity Act in the state of Oregon (where I practice pediatric palliative care) or Canadian legislation permitting clinician-administered medical assistance in dying and active euthanasia [10]. The "scandal logic" is vivid and persuasive.

Admittedly, the majority of cases and claims of suffering in pediatrics are less sensational than those involving neonatal euthanasia. These cases and claims occur most frequently in spaces where children with serious illnesses and life-limiting diagnoses have their lives prolonged by invasive technology-intensive care units are common examples [11-13]. Yet the suffering-as-scandal and suffering-as-mirage tropes are also ubiquitous in these locations [3].

The problem with both of these uses of the label of suffering is that, whether utilized to justify infanticide in a baby with spina bifida or denied to justify placing a tracheostomy in a neurologically devastated patient, they often pay little heed to any particular child. In other words, neither perspective-suffering as scandal or suffering as mirage - is sufficiently accountable to the individual child at hand, such as baby Esther herself, or accounts for what kind of thing a child actually is. Instead, the label of suffering floats freely above the body of the child, untethered from any objective set of criteria [4, 14]; and, because it is untethered, it is free to underwrite

\footnotetext{
Footnote 4 (continued)

as-mirage logic was also the triumphant logic in the well-publicized legal case of the brain-dead but not (totally?) dead child Jahi McMath, whose parents were allowed to move her to New Jersey, a state with laws more accommodating of patients whose families do not accept the brain death criterion for death [8]. In my clinical experience with these kinds of cases, staff are often extremely distressed and request that the hospital stop "causing suffering." However, treatment often does not stop, since there is a more powerful claim that individuals can neither be harmed nor suffer if they cannot have a cognitive or mental experience. Here one can at first see a tension between two suffering logics; but then, as the mirage logic triumphs in clinical discourse, claims of patient suffering come to be understood as (merely) gesturing toward a mirage. To observe the mirage logic at work in published literature, see Joan Henriksen and Elliott Weiss's argument that parents' perspectives regarding their child's suffering and quality of life must always be taken "at face value" and clinicians who see suffering where parents do not are therefore incorrect in their assessment [7, p. 3].
} 
whatever preconceived notions about profound disability, or whatever emotional reactions to extreme childhood illness, adults who speak on the child's behalf may harbor. Therefore, to clarify a philosophically confusing concept and to prevent suffering from becoming the "new futility" as Salter has warned [4, p. 17], a theory of pediatric suffering is required. I now turn to the literature to see if a satisfactory theory can be identified.

\section{Pediatric suffering: What has experience got to do with it?}

Most modern theories of suffering consider suffering to be a species of negative subjective experience. A subjective experiential component of suffering is present, for example, in the theories of Eric Cassell [15], Jamie Mayerfeld [16], Michael Brady [17], Fredrik Svenaeus [18], David DeGrazia [19, 20], Erica Salter [4], Laurel Copp [21], Steven Edwards [22], and James Davies [23], among others. For Cassell this experiential component is distress; for Mayerfeld negative feelings; for Brady undesired unpleasantness; for Svenaeus a negative phenomenological mood. For some, like Cassell, the undesirable experience is suffering in toto; for others, like Brady, it is necessary but not sufficient (as I examine in detail below) ${ }^{5}$ Despite their differences, all of these writers affirm that some undesirable subjective experience is necessary for suffering.

The experiential condition poses a challenge for understanding the suffering of very young children and children with profound cognitive impairment. Individuals in these categories cannot describe their experiences. As a result, their minds, emotions, and feelings remain largely opaque. As mentioned, this opacity is unproblematic for Cassell's account, which holds that language, cognition, and a futureoriented imagination are minimal requirements for suffering. Accordingly, Cassell bites the bullet and concludes that many humans and most nonhuman animals cannot suffer.

\footnotetext{
${ }^{5}$ One reason an analysis of suffering is so difficult is that suffer is polysemous, with an objective sense as "to undergo a hardship" and a subjective sense as "to endure an unpleasant, consciously experienced mental state." David DeGrazia draws a clear line between these two senses [19, p. 135]. Others, like Michael Brady, suggest that the border between these two senses may be porous [19, pp. 11-12]. Some authors, like Eleonore Stump, believe that suffering has two distinct but intertwined and overlapping dimensions, with both dimensions relating to the undermining of human flourishing [19, 19, 24]. My own view is not dissimilar [25]. Regardless, I suspect that the key to really understanding suffering is to see past facile differences between word senses or dimensions and recognize that suffering is necessarily a public phenomenon (as I will explore later), in that suffering seems to require more than a bare mental state and is always grounded in the judgments of a speech community.
} 
Yet this conclusion is unsatisfactory. ${ }^{6}$ Newborns, infants, and patients with severe cognitive impairment can certainly experience more than bare pain; indeed, the claim that children who are prelingual or otherwise lack language and self-awareness can suffer is supported intuitively, ${ }^{7}$ as well as by a robust consensus of parents and pediatric clinicians, both anecdotally and in the published literature. ${ }^{8}$ Whether due to social, spiritual, psychological, existential, or biological factors, it is broadly acknowledged in pediatrics that all children can suffer, even those who cannot reflect upon or articulate their suffering.

In recognition of the reality of pediatric suffering, a number of philosophers have attempted to construct a more accommodating experiential theory of suffering that is inclusive of children. Two stand out for their comprehensiveness and rigor. I will examine these in turn; in doing so, I aim to show a fortiori why experiential (or subjective or psychological) theories of suffering fail to adequately capture or elucidate the nature of pediatric suffering.

\section{Two experiential views of suffering}

Mayerfeld, a political theorist, has sought to shed light on the immensity and preventability of human suffering. His goal is to explicate the nature of the duty to relieve suffering in order to drive political reform. As a utilitarian, he employs the conceptual machinery of Jeremy Bentham, John Stuart Mill, Henry Sidgwick, and Derek Parfit to structure and motivate his arguments.

For Mayerfeld, "to suffer is to feel bad" [16, p. 11]. He views suffering as the negative end of a spectrum of feeling: suffering is at one end and happiness is at the other [16, p. 12]. Or, as he puts it, suffering and happiness sit at opposing ends of a "one-dimensional scale" [16, p. 29]. Notably, Mayerfeld rejects an Aristotelian understanding of happiness as flourishing or eudaimonia. Instead, drawing on

\footnotetext{
${ }^{6}$ It is unsatisfactory and incomplete because, as Stan van Hooft has argued [26], it denies the suffering of people who are suffering almost prototypically. For example, it denies the suffering of people lacking insight into their own experience, such as a child in an exploitive sexual relationship whose trauma is normalized by the perpetrator, a gratified drug addict who pays for heroin with prostitution and crime, or a avaricious billionaire whose pursuit of power and money means she seldom sees her family [25, p. 99]. These people are ostensibly all suffering in important ways, even if they themselves would deny it; it follows, then, that individuals are not always the most authoritative judges regarding the presence or absence of their own suffering. This claim is also corroborated by the field of trauma therapy, which has long recognized that individuals are not always the best arbiters of the degree to which they are suffering or have suffered in the past [27, 28]. Once this Cassellian subjectivity or self-reflection condition for suffering is recognized to be false, the door is open for all sorts of beings (human and nonhuman animal alike) to have the capacity to suffer.

7 I believe that a defeating and intuitive (albeit horrifying) counterexample to Cassell's idea that young children cannot suffer is presented by imagining a newborn who is being slowly boiled alive by a sadist. By any intelligible account, the newborn would be suffering, and as I argue below, this sense that the newborn is suffering contains a strong and intrinsically evaluative claim that things could not get much worse for the newborn.

${ }^{8}$ For a variety of claims, taken from published medical literature, that prelingual or cognitively impaired/obtunded children can (still) very much suffer, see [7, 11-13, 29-31].
} 
Epicurean hedonism, he selects an idea closer to "enjoyment" as suffering's opposite [16, p. 12]. He eschews Aristotelian eudaimonia-which sees wisdom, rationality, and the achievement of important life goals as requirements for human flourishing-because this view denies that babies can flourish, or be happy in the deepest and most meaningful sense, given that babies lack virtue. Mayerfeld, contra Cassell, wants to construct an all-inclusive theory of human suffering. To achieve this, he constricts the suffering-happiness continuum by pruning the requirements for suffering or happiness. ${ }^{9}$ In so consolidating the suffering experience into a state of mere "disagreeable overall feeling" at any particular moment [16, p. 14], Mayerfeld is able to lower the bar for suffering and democratize the suffering experience. Specifically, on his theory, if a disagreeable overall feeling is worse than unconsciousness, it is suffering; hence even mild boredom or impatience can qualify [16, p. 16]. Mayerfeld's suffering has few criteria.

But this theory also has serious problems. Mayerfeld's most consequential problem is the way in which he flouts ordinary language (a critique that will be a theme throughout my analysis). This flouting occurs in two discrete ways. First, Mayerfeld claims that suffering is a feeling - that one can, in fact, feel suffering [16, p. 52]. But this claim seems mistaken. One cannot feel suffering any more than one can feel sitting or feel eating. Consider sitting. People or animals are sitting when their legs are bent (or not), their rumps are on the ground, a chair, or a stool, they are neither standing nor lying down, and so forth. There is of course a feeling to sitting —or, put more accurately, there can be a whole host of sensations (pressure on the derrière) or emotions (relief after a hard day, joy after a marathon) that may accompany the state of sitting. However, these diverse feelings are neither necessary nor sufficient: one can fall asleep but still be sitting if other criteria are fulfilled. The same is true of eating. Eating can evoke myriad sensations, but it can also presumably be accomplished sensation-free (as when I zone out but regrettably devour a bag of potato chips). Suffering is not dissimilar to these experiences: it is not a tangible sensation to be felt but a broader disposition in which one feels. ${ }^{10}$

As I see it, suffering is a state of existence and is not reducible to bare unpleasantness. With word use as a plumb line, it appears that suffering and happiness, at least as the concepts are construed by Mayerfeld, do not exist on a spectrum at all insofar as to be suffering and to be happy are not in fact the same category of predicate. It makes perfect sense to say "I feel happy" while eating ice cream or hugging your child; yet it would sound quite odd to say "I feel suffering" after stubbing your toe, losing bowel function after a spinal cord injury, or hearing that a close friend has died. Moreover, suffering is not gradable by degree in the same way that being happy is: there may be a "very happy" person but not a "very suffering" person. One simply is (or is not) suffering. Suffering is a description of a life going poorly,

\footnotetext{
9 To be clear, Mayerfeld does not discount flourishing or well-being. He simply views happiness, in his contracted terms, as one experiential dimension of well-being, noting that there may be others, such as morality and rationality $[16, \mathrm{p} .12]$.

10 By "disposition" I mean the way in which something is placed or arranged, especially in relation to other things. Notably, this is also what I mean when I refer to suffering as a "state of affairs."
} 
a recognition of a bad state of affairs. Moreover, as Eleonore Stump discerns, in order to understand suffering generally, it is first necessary to understand how suffering works in the lives and stories of particular people [24]. Merely pointing to an abstract feeling and calling it suffering does not explain what it means to suffer.

Another problem for Mayerfeld is that by lowering the bar for what counts as suffering, he stretches the concept beyond intelligibility. The consequences of this overextension are germane to pediatric suffering. For example, because children can lapse quickly into tantrums and emotional meltdowns (which ostensibly feel quite bad to them), he claims that children "fall easily into moments of intense suffering and unconsolability" [16, p. 33]. This claim is bizarre and appears to be at least prima facie false: a child screaming at the supermarket may be feeling fear, pain, frustration, or the disorienting effects of a missed nap, but that does not mean that he is suffering. As Cassell would likely retort, there is no need to "discover" suffering where existing descriptions - fear, pain, frustration, and fatigue - sufficiently represent the situation. Furthermore, equating quotidian tantrums with suffering trivializes the word and bleaches its meaning; it robs it of its purchase on reality and weakens its ability to actually portray the world. Human beings frequently find themselves in situations where a rote list of feelings cannot adequately represent the evil, torture, betrayal, afflictions, tragedy, and injustice that they endure. It is for situations such as these that we have a concept of suffering.

If suffering is more than merely a bad feeling, then it is not accurate to say that newborns or children with cognitive impairment are necessarily suffering any time they feel bad. Indeed, feeling bad is a daily, ever-fluctuating part of all children's lives. ${ }^{11}$ Yet if experience remains a critical component of suffering, as it seems it must, and these categories of children are thought to be able to suffer, what kind of experience is one referring to when one talks about their suffering? Could their suffering be a state of affairs, albeit one that is thoroughly experiential?

Brady attempts to answer this question in his book Suffering and Virtue [17]. His overarching goal, in contrast to Mayerfeld's, is to demonstrate why suffering is in fact necessary for human flourishing. This is a sizable claim, and I will not attempt to evaluate it here. Rather, I will examine his theory of suffering only in order to show why it too is inadequate for pediatrics.

Brady advances a desire view of suffering. He begins by identifying "negative affect" as one essential feature of experiential suffering [17, p. 16]. This negative affective component is common to the two categories of suffering he considers: physical and mental. Physical suffering is always "about the body" [17, p. 14], meaning that some part of the body is always the intentional object of experiencethat is, what the suffering is about. Examples of physical suffering include pain, itchiness, and fatigue [17, p. 13]. Mental suffering may be comprised of either negative "emotional" states, like shame or rage, or negative "mental" states, like loneliness, boredom, or spiritual pain [17, pp. 14-15]. Emotional and mental states are

\footnotetext{
11 The everyday volatility of children's feelings is, incidentally, not so different for the rest of us. J. D. Salinger captures this sentiment in his oft-quoted line from Franny and Zooey: "I can't be running back and forth forever between grief and high delight" [32, p. 62].
} 
distinct in that emotional states have a clear target-a "motivational" or "actional" element-whereas mental states lack motivation and tend to have a wider target, like depression, or even "no target at all," like some types of anxiety [17, p. 15]. So, for instance, a negative emotional state like shame will have a perception (e.g., your teacher sees you cheating), an evaluation (e.g., you think, your action was wrong), a feeling (e.g., a tightness in your chest), and an action (e.g., an apology or cover-up lie), all oriented toward a target, namely, what you did [32, pp. 9-10]. Mental states, conversely, are more like moods: they have a "distinctive feeling" and saturate one's perceptions and experiences [32, p. 16]. Yet both mental suffering (negative emotional or mental states) and physical suffering share a negative affect-that is, they all "feel bad or feel unpleasant" [17, p. 16].

However, pace Mayerfeld, Brady recognizes that negative affect that falls below a certain qualitative threshold is insufficient for suffering, since it is obvious that "merely being the subject of an unpleasant experience isn't enough to make one a suffering subject" [17, p. 23]. Hence, to demarcate suffering, he introduces the idea of occurrent desires, or desires that are "active and operative" and "involved in motivating action" [17, p. 29]. Specifically, he posits that suffering comprises two coexisting desires —one affective and one occurrent.

The first desire is internal to any unpleasant experience. As Brady explains meticulously, an experience is unpleasant if and only if it is composed of a relation between (1) a sensation and (2) a desire that the sensation cease. He compares this relation-which contains a negative evaluation within its essential structure- to the strength of a loving relationship or the unfairness of a fight [17, p. 49]. The unpleasantness is "a property of the relation itself, rather than a property possessed by one of the relata" [17, p. 48], meaning that it is the quality and intensity of the relation between the sensation and one's desire for it to cease that determines the nature and degree of unpleasantness. Unpleasantness is thus an alloy. So, presumably, there may be nothing unpleasant about a small amount of nausea or loneliness; however, once the subject begins to desire that the nausea or loneliness cease, the sensation becomes unpleasant. Accordingly, Brady rejects all forms of philosophical "internalism," which maintain that unpleasantness is a particular kind of feeling intrinsic to every negative sensation $[17$, p. 32].

To move from an unpleasant experience to suffering, Brady introduces a second, occurrent desire - the desire that the "unpleasant experience not be occurring" [17, p. 55]. Put differently, to suffer is to mind, care about, or have some negative attitude toward a coincident unpleasant experience. His theory therefore remains experiential. For Brady, suffering simply is the first-person experience of having the desire to not have the negative experience that one now has.

Brady's theory is complex and detailed, and I do not claim to do it justice here. Yet even in outline it is powerful and can elucidate many cases of suffering. For example, it can explain why a person is suffering when she thinks her leg pain indicates a deadly osteosarcoma, but no longer suffering when she discovers that the pain is actually caused by overtraining for a marathon. The pain is still unpleasant, but now she no longer minds the pain-in fact, she may even relish it as a sign of her improving fitness (no pain, no gain!). 
However, I do not believe that Brady is as successful when it comes to explaining the suffering of young children or children with profound cognitive impairment. His relative lack of success on this point may in part owe to a lack of relevant examples. In a critique of Cassell, Brady contends that both a teething infant and a fox with a broken leg suffer, despite being unable to consider the larger significance or meaning of their pain [17, p. 26]. His position that the infant and the fox can suffer is based on the conviction that young children (and animals) are "capable of desiring that their situation be otherwise" [17, p. 27], thereby fulfilling the occurrent desire requirement for suffering.

I am uncertain what to make of this claim. Can an infant have occurrent desires? What about a full-term newborn, a twenty-five-week prematurely delivered newborn, or a fetus at fifteen weeks' gestation? Brady does not spell out what the phenomenology of a newborn's "conative attitude" toward a negative experience could be [17, p. 27], but instead connects it to the easy-to-imagine desires or attitudes of a cognitively typical adult human. This conflation creates several problems for his ability to maintain an all-inclusive account of suffering. For one, his account rests on the epistemologically fragile assumption that newborns and infants with serious cognitive impairment can have wishes. How can one know this? If a newborn retracts her leg while her foot is being tickled, is she expressing a wish that her foot were not being tickled? Here one must be careful not to project phenomenal consciousness onto the behaviors of newborns. ${ }^{12}$ I suspect Brady's conflation of desires subtly stretches the meaning of the term (a sort of bait and switch) so as to create the illusion of a single unified understanding. For instance, Brady notes that to desire something implies a responsiveness to "assessments of the importance of the situation or object" [17, p. 27]. Yet there is no good reason to think a newborn or a child with profound cognitive impairment can make such assessments. Newborns act largely out of instinct and reflex. ${ }^{13}$ Moreover-and here is the critical pointwhatever assessments of unpleasant experiences a newborn can be expected to make cannot count as suffering.

To see why this is the case, consider what a newborn does. Newborns eat, sleep, stool, urinate, and cry. These are the normal and daily cycles of neonatal life. Specifically, newborns tend to cry when they are hungry, pooping, or unswaddled; presumably, they are unhappy outside of the dark, warm, constrained space of the womb. But does a newborn "mind," and therefore suffer, when she is hungry or her intestines are contracting uncomfortably, occasioning her to scream out in response? This is a hard question to answer. Yet my response is that it does not matter. It does

\footnotetext{
12 Per DeGrazia, phenomenal consciousness "involves subjective, qualitative experiences and not just the processing and coordinated deployment of salient information ... or [merely] the state of being awake" [19, p. 142].

13 A dive into the literature on newborn cognition is beyond the scope of this paper. However, recent scholarship has established that newborns-while largely instinctual and reflexive creatures at birth (studies on newborn, not infant, cognition are limited)—rapidly develop cognitive capabilities for selection, discrimination, and so forth [34]. Moreover, it is extremely difficult to know when an instinctual behavior becomes a planned or reflective behavior for a developing child. Regardless, it is clear that newborns develop fast and do so best through social interaction [35].
} 
not matter if the newborn minds these unpleasant feelings because they are a normal and necessary part of her growth and development; and because these unpleasant feelings are a normal and necessary part of her growth and development, it is unintelligible and counterintuitive to say that the newborn is suffering when she experiences them. A healthy but crying newborn may be hungry or need to be swaddled, but to conclude that the newborn is suffering because she is crying is incorrect.

Newborns are not said to be suffering in these situations because, on a basic level, it is recognized that claims of suffering (at least in the case of a newborn) contain a necessary element of judgment and evaluation. To say that a newborn is suffering is to judge that she is doing poorly, that a pain is bad for her on the whole and is part of or contributing to the frustration of her growth, development, and flourishing qua newborn. In fact, this necessary evaluative element is not limited to the suffering of newborns. Pain, even undesirable pain, is not considered suffering when it is judged to be requisite and critical for a newborn to grow into an infant, an infant into a toddler, a toddler into a child, a child into an adolescent, and an adolescent into a functioning and well-adjusted adult. For example, the physical and emotional pain associated with discipline (e.g., swatting a child's hand away from an electrical outlet or forcing an adolescent to admit to and apologize for stealing) is often deeply "minded" by children and adolescents but not considered suffering. It seems therefore to be the case that a full account of the suffering of children cannot be given without an objective teleology - that is, without understanding a child's life in reference to a species-specific end, goal, or purpose. These ends, goals, and purposes are accountable to standards of flourishing that are independent of the individual child's subjective experience. Again, to understand suffering one must first understand what a thing is; to understand suffering is to understand a life.

These sundry reflections have led to my own view, which I have described at length elsewhere [3], that suffering must be understood as having both subjective and objective dimensions, dimensions which may or may not be able to be folded into one overarching theory. I understand subjective suffering to be a bipartite state of affairs consisting of (1) a negative affect, seen as a phenomenological mood, and (2) a loss of one's sense of self, seen as a loss of one's relationships, roles, or narrative. Following Stump, I understand objective suffering to be the absence of speciesspecific flourishing. I believe this conceptualization has the greatest fidelity to ordinary human life and language (for instance, in my clinical experience, patients and families generally describe suffering as having these two interweaving dimensions: they both feel bad and have lost something dear to them). Moreover, and along similar lines, a two-pronged view helps to avoid a peculiar concession many writers have been willing to make-namely, the concession to "bite the bullet" and declare that certain individuals are suffering even when describing them as such feels misplaced or superfluous. ${ }^{14}$ But this bullet-biting should be avoided. For as C.S. Lewis notes,

\footnotetext{
14 For instance, Brady says he will "bite the bullet" and admit that based on his theory, those who have a mildly unpleasant experience which they slightly mind are suffering, like someone unhappy about being downgraded from first class to coach on an airplane [17, pp. 28-29]. In my mind, our hesitancy to grant this person the description of suffering suggests that all suffering is accountable to something other than mere experience.
} 
while language is never an infallible guide, "if you begin by flouting it, it has a way of avenging itself later on" [36, p. 2]. We cannot make words mean whatever we please.

More germanely, these reflections demonstrate that to understand the suffering of young children, or children like Esther with profound cognitive impairment, a purely experiential account of suffering will not suffice. Instead, a sociologically informed, objective theory is required. This objective theory of pediatric suffering must be accountable to the individual child at hand, such as baby Esther herself, and be able to account for what kind of thing a child actually is. I will now attempt to outline just such a theory.

\section{Toward a theory of pediatric suffering}

To begin, I wish to pose the following question: what are the conditions under which an unimpaired, healthy baby is said to be suffering? Unimpaired healthy-born babies are said to be suffering when they are experiencing a set of absences-absences of conditions such as warmth, protection, shelter, human touch, freedom from gratuitous pain, access to the right kind of milk, or as they grow older, eye contact, parental and peer engagement through language and play, provision of age-appropriate food, love, comfort, and discipline. An evaluation of these absences reveals the exquisite dependency of children. Children generally, and babies in particular, can do virtually nothing on their own. They exist as contingent beings, meaning that they can continue to exist only insofar as they are the recipients of time, energy, and care from those who can and do act in their favor. ${ }^{15}$

This ineluctable fact of human existence-that children are creatures of exquisite dependency - is identified by Alasdair MacIntyre in Dependent Rational Animals as a feature of central importance to human life and flourishing:

We human beings are vulnerable to many kinds of affliction and most of us are at some time afflicted by serious ills. How we cope is only in small part up to

\footnotetext{
15 As the developmental psychologist Michael Tomasello has argued, it is the emergence of the capacity for joint attention at nine months of age that is the foundation for human uniqueness insofar as the cultivation of joint attention-which requires frequent engagement with and attention from caregiving adults-develops into the ability for shared intentionality, the creation of socially shared realities, and mature and coordinated self-other perspective taking. These are skills that no nonhuman animals have been shown to possess [34, pp. 43-90]. Moreover, to the extent that the uniquely human language capacity issues from the ability to distill and integrate patterns of sounds, Tomasello's claims dovetail research by Patricia K. Kuhl and colleagues [35, 37], who found that nine-month-old infants with English-speaking parents were able to retain the same Mandarin phonetic contrasts as infants raised in Taiwan when the former had in-person interactive language exposure sessions with a Mandarin speaker, but not when they listened to Mandarin language exposure sessions on the television. In this way, the interactional cultivation of infants' capacity for joint attention can be seen as prerequisite for membership within the speech communities that form their social realities, as "functionally integrated social systems with shared norms of evaluation" [38, p. 26]. (Thanks to Katelyn MacDougald for pointing me to Kuhl's work.) So, in a very real sense, an individual child can hardly "become human" without the gift of care and love from people who can and will act on the child's behalf.
} 
us. It is most often to others that we owe our survival, let alone our flourishing, as we encounter bodily illness and injury, inadequate nutrition, mental defect and disturbance, and human aggression and neglect. This dependence on particular others for protection and sustenance is most obvious in early childhood and in old age. [39, p. 1]

For MacIntyre, then, while individual human flourishing is inextricably bound up in the lives of other people, the flourishing of the very young is an absolute impossibility outside of unidirectional relationships of care. Yet flourishing and suffering, at least for the very young, seem to exist on a continuum, for the very conditions whose absences are constitutive of infant suffering are necessary and sufficient for a healthy and unimpaired infant to experience flourishing. Hence, just as children (unlike adults) cannot effect their own flourishing, so are children neither responsible for nor capable of allaying their own suffering. Adults can put on a sweater when they are cold, eat when they are hungry, and move to a new city and reinvent themselves when their lives have grown stale. Young children-and some people living with disability - do not have these capacities. Rather, children always rely wholly on others to resist suffering, grow, and flourish. Importantly, this ineradicable dependency necessitates that pediatric suffering be understood as a social and political event. There are times when children are born into the world parentless and require a community of caretakers in order to flourish and avoid suffering; in these circumstances, suffering is an inescapably social phenomenon. Similarly, and by extension, it is not uncommon that a community's generosity or resources to care for its young are exhausted, and accordingly the conditions for flourishing become incumbent upon the polis to provide. The Americans with Disabilities Act of 1990 or the Children's Health Insurance Program (which gives matching funds to states to provide health insurance coverage to families whose incomes are modest but too high to qualify for Medicaid) are examples of political recognition and response to dependency.

So for healthy, unimpaired children at least, suffering is the lack of conditions under which they can grow and develop normally into healthy youngsters, adolescents, and adults. In fact, this natural teleology is not unlike other life forms, such as mushrooms, petunias, or giraffes. Indeed, MacIntyre notices this same feature of the natural world:

What it is to flourish is not of course the same for dolphins as it is for gorillas or for humans but it is one and the same concept of flourishing that finds application to members of different animal - and plant—-species. ... What a plant or an animal needs is what it needs to flourish qua member of its particular species. And what it needs to flourish is to develop the distinctive powers that it possesses qua member of that species. [39, p. 64]

He goes on to conclude that it is a "question of fact" [39, p. 64] whether or not a member of a species is flourishing (or, I would add, suffering), holding that successfully distinguishing which members of a species are flourishing "involves identifying the various characteristics that an individual or population of some particular species needs in order to flourish in this or that particular environment, at this or 
that particular stage of development" [39, p. 65]. Hence, flourishing and suffering are partially demystified and desubjectified. For young children at least, flourishing and suffering can be seen as empirical facts accountable to empirical standards, not unlike empirical standards of population success or failure identified by biologists for bottleneck dolphins or Euterpe precatoria trees populating the Amazon rainforest. ${ }^{16}$

However, the analysis is still sitting in the realm of universals; to accurately understand and describe the flourishing or suffering of a child with profound disability and cognitive impairment like baby Esther, one critical move must be made. Where MacIntyre broadly describes homo sapiens as a uniform representation of a natural kind, one must imagine instead a quilt of variegated materials, textures, and complexities. Human life contains within it a spectrum of individuals, each with their own trajectory, their own telos, and therefore their own unique set of needs. A baby with lissencephaly like Esther will never walk or talk or feed herself or articulate preferences that could subsequently be satisfied. Baby Esther will live for a few months or a couple of years, likely with a feeding tube, and then she will die. The arc of her life will descend swiftly; her flame may even burn out before her doctors' very eyes. But this does not imply that Esther's suffering is somehow of a different nature or decibel than any other newborn child (cf. [45]). All children lay a claim on us. ${ }^{17}$ All children demand a level of care from older individuals who are in a particular position and have a particular relationship to them if they are not to suffer.

Esther can still receive, and likely even appreciate in her own way, love, warmth, milk, and gentle touch. For Esther, these are the forms that care will take on, the ways that health care can be provided and suffering held at bay. As Gina Campelia and colleagues point out in this special issue [49], within the context of a family, care, flourishing, and suffering are all deeply entwined. Parents see suffering, and

\footnotetext{
16 To be clear, I am not thereby advocating for a "neutral" position on suffering and flourishing reminiscent of Christopher Boorse's "value-free" constructions of health and disease [40, 41]. I believe that everything is interpreted to some degree; hence the question becomes not if, but how, why, and to what extent local cultural values shape our interpretation of species-specific suffering and flourishing. For young human children, much more so than for human adults, the criteria for what kind of lives are going well or poorly are universal. This is due largely to the way in which children's biological development has a logic and pattern grounded in their physical bodies, and therefore (to appropriate Tristram Engelhardt's discussion on the motley nature of value judgments in medicine) what counts as their suffering and flourishing "need not presume transcultural values" in order to be intelligible [41, p. 204]. Hence, my method (but not my starting assumptions or conclusions) follows Martha Nussbaum's method in her construction of "Aristotelian essentialism," in which she set out to identify features of human life that are critical for human flourishing, many of which are connected to human embodiment [42, pp. 214-223]. Here I am also influenced by Philippa Foot's methodological discussion in 43Natural Goodness, especially chapters 1-3 [44]. I appreciate Devan Stahl for pushing me to clarify these points.

17 One might ask, "Really? All children?" Yes, I would respond, all children. Hence I disagree with Nussbaum, who argues that at some profound levels of cognitive disability, human beings do not have or cannot participate in a "human life" at all [46, p. 181] and are therefore outside of even the farthest frontiers of justice. By contrast, I think that Stanley Hauerwas [47] and Timothy Chappell [48] are correct in their less capability-focused understanding of human life and rejection of "criterialism" when discussing persons and personhood. A deeper dive into why I agree with them and not with Nussbaum is beyond the scope of this paper, although I do sketch one reason in my penultimate section in my brief discussion of Eva Kittay.
} 
suffer themselves, when their child's needs cannot be met and when they feel their love and duty to care for their child is being obstructed by illness. In families, suffering is often dislocated from the individual and spread between and throughout its members. As relational bonds between parent and child grow and evolve-bonds of recognition that, as James Mumford has described [50], begin to form well before a child is born or a "terminal" diagnosis like lissencephaly is delivered-parental identity becomes knit together with child identity. And because a loss of identity is constitutive of suffering [25], when illness erodes these relational bonds, the relationship may suffer, and with it, the individuals who are defined in and through those bonds. Hence family concerns about patient suffering could in fact be a manifestation of the family's own suffering.

From a medical perspective, if Esther is suffering because of pain or cold or overstimulation from neuroexcitability, these symptoms can be assuaged with opioids, radiant warmer beds or skin-to-skin contact, and careful regulation of noise and bright lights. Absences of comfort and care-absences that would otherwise constitute her suffering — can be filled. These absences will be unique to Esther. They will evolve daily. Yet as long as they are addressed, her suffering will be ameliorated and she will, I believe, flourish.

\section{Can Esther flourish?}

It may seem strange to think of Esther as flourishing. I presume this is because of our (Western) culture's obsession with freedom, intelligence, rationality, beauty, and self-expression. None of these attributes are available to a child like Esther. It seems strange to imagine Esther as flourishing, therefore, since she cannot partake in these aspects of the good life. However, as MacIntyre and others working in care ethics have shown, relationships of care can in fact constitute and sustain flourishing. ${ }^{18}$ Still, even granting that Esther can flourish, the time will inevitably come when Esther begins the process of dying. And when those moments of dying arrive, Esther will manifest a different kind of flourishing and require a distinctive flavor of care to stave off suffering - a care that in the medical profession is called palliative. As is often the case when a child has a life-limiting diagnosis, there is a ceiling to both parents' and medicine's ability to provide the kind of care that will prevent the child's suffering or the kind of treatments that will prevent the child's death. When

\footnotetext{
18 So why does this way of thinking persist, in bioethics and beyond? At best, I see it as a failure of imagination. At worst, I worry it represents what Rosemarie Garland-Thomson calls "eugenic logic"that is, an understanding of disability that "tells us that we can avoid disability and even eliminate it from the human condition" [51, p. 342] and furthermore that "our world would be a better place if disability could be eliminated" [51, pp. 339-340]. I suspect this logic is at work, behind the scenes at least, when someone like Jeff McMahan calls an anencephalic infant an "utterly failed human being" [52, p. 13]. It seems to me that the implication of such a description is that you should get rid of or replace said human being, in the same way you should get rid of or replace (or eliminate) other "utterly failed" things, such as a broken bicycle or blender. While I cannot explore this worry further here, it seems to run parallel to Salter's concern that claims of suffering may mask moral appraisals of what kinds of lives are worth living.
} 
that ceiling is reached, I suspect that we all, clinicians and parents alike, must learn to have the courage and wisdom to release the baby from the clutches of technology and recognize the great tragedy of this mortal life - that the people we love the most will all die.

The hope of palliative care- a practice founded on the belief that suffering can be diminished if careful and appropriate medical care is given to dying patients-is that even in death more than a modicum of flourishing can be secured. How can human beings die well in the modern age? How can baby Esther die well, and how can she and her family not be consumed by suffering in the process? I think that by surrounding Esther's family with love and care, engaging them in honest conversations about faith and meaning, and treating Esther's symptoms with medicines and technology, the absences that would constitute their suffering can be filled for a time. However, at some point, Esther's life-continuing treatments will inexorably begin to create suffering (in the form of pain, vomiting, anxiety, seizures, dyspnea), rather than preventing it. When that point is reached, in my opinion, this is a sign that the loving and felicitous course is to allow Esther to die. Yet there is still something for medicine to do. In those moments, I am convinced that simple and practiced human presence can fill the absences that are constitutive of suffering, help Esther's family resurrect their narrative, and perhaps even set them on a path of flourishing for the future. Suffering may be overcome.

\section{Connections and implications}

In my view, child suffering is the absence of child flourishing. Child suffering is a state of affairs described in reference to an objective set of culturally embedded, species-specific conditions. To say that a child is suffering is to make an evaluative and judgmental claim about the child. It means that life is going poorly for her or him.

However, because to say that some child is suffering is to make a claim about that particular child, pediatric suffering is sensitive to the unique characteristics of each child. In pediatric medicine, for instance, each patient will have distinct medical needs and exist within a unique clinical and historical context. Hence what is necessary to prevent suffering and actualize flourishing will always differ from patient to patient.

The implications of this view are not inconsequential. When child suffering is defined as an absence of the conditions for flourishing, it becomes difficult to maintain that a baby like Esther, especially one born in the twenty-first century United States, will necessarily have a life of suffering. The untenability of this position extends to many children born with trisomy 13 and 18, complex congenital heart disease, and certainly Down syndrome. On the other hand, a child born with type II osteogenesis imperfecta or epidermolysis bullosa, two diagnoses that have actually led to euthanasia in the Netherlands under the Groningen Protocol [53, 54], may legitimately experience refractory suffering, as these diseases can lead to virtually unmanageable pain.

My view will also be constructive for pediatric practice. Two examples (modified for anonymity but taken from my own clinical practice) are relevant. 
Example 1. A baby is dying from heart failure in the pediatric intensive care unit (PICU) and experiencing dyspnea (shortness of breath), a common feature of advanced heart failure. The parents refuse to consent to treatment with opioids, which relieve dyspnea, because they worry it will hasten death (it will not, if given in small doses and carefully monitored). Maximal respiratory support and sedation have been tried and found to be ineffective at controlling the dyspnea (short of a breathing tube, which the parents have also declined). The PICU staff is experiencing moral distress and worry that the child is suffering. In this case, by my view the child is suffering, and by respecting parental authority and not giving opioids, the PICU is in fact causing further suffering and thereby harming the patient. Because a pediatrician's duties lie first and foremost with her patient, in my opinion, parental authority should be overridden and opioids should be given.

Example 2. A ten-year-old previously healthy girl has a stroke. Prior to her stroke, she was a select soccer player and very advanced in academics. Her parents are early-career professors; they value her precocious intellect. After the stroke, the girl has profound cognitive disability. One month post-stroke, she cannot feed himself, walk, or say words. It is uncertain if she can discriminate between her parents and strangers. However, she can sit up and swat at toys and appears to enjoy being fed. She occasionally cries out in what may be pain or fear; medications and soothing touch help calm her. The parents decline the placement of a feeding tube because they "know she would not want to live like this," and ask to take her home and let her die by dehydration and starvation. They state that to continue to live would cause unbearable suffering to their daughter; they also explain that they do not have the time or resources to properly care for her. Based on my view, the medical team can deny that the patient is suffering or necessarily will suffer. However, the prevention of her suffering will depend on her parents' care (which may force them to sacrifice other goods), their friends, family, and community, and robust social services.

\section{Concerns}

What I have presented in this paper is only an outline of a theory. Many of the concepts, such as suffering as state of affairs, culturally/contextually embedded conditions for suffering, and suffering and harm, need to be further populated.

This theoretical outline may raise objections and questions. I will consider three. First, someone might object that my view-that suffering and flourishing exist on a continuum - is false because it does not apply to adults. It may in fact be the case that my view does not apply-to adults. Adults are not just big children and should not be treated as such. ${ }^{19}$ Thinking, language-using adults can evaluate their own lives and often choose suffering, if it is in service of their hearts' desires. In so

\footnotetext{
19 As MacIntyre notes, although adult human flourishing is "itself a question of fact" for thinking, selfreflecting humans, "what it is to flourish has to be answered in part through evaluative and conceptual enquiry" [39, p. 64].
} 
doing, their agency is sustained, and they (ostensibly) flourish; death by martyrdom or in service to one's country are possible examples.

Second, someone might worry that the objectification of child suffering could serve to underwrite certain actions as morally acceptable that as a rule are not; infanticide is an example. However, such an argument would be a mistake. It is plausible that the impulse to relieve suffering can serve as a prima facie reason to act, but not as a pro tanto reason or ultimate justification. This tension is illustrated by the endless debates surrounding physician-assisted suicide and in the challenging idea of transformative suffering found in many religious traditions.

Third, someone might question how my view would handle a patient with no neurological function at all, such as a patient who is brain dead or in a persistent vegetative state. Does recharacterizing suffering as a bad state of affairs and pediatric suffering as the absence of flourishing commit me to saying that a brain-dead child (who presumably can have no first-person experiences) is suffering because she is not flourishing? I think that the answer depends on how the situation is described. On the one hand, yes, the child is suffering. As Stan van Hooft observes, on a primitive level, suffering always connotes a "departure from how things should be" [55, p. 14]. Within the claim that a brain-dead child is suffering is a normative evaluation that things are not as they should be for the child, ${ }^{20}$ and an implicit judgment that hospitals should not be keeping the molecules of brain-dead people in motion. This sentiment is expressed in hospital staff's frequent cries that a brain-dead child being maintained on a ventilator is suffering and worries that they are participating in something wrong. It feels like dead people ought to be allowed to die, and to keep them alive is to commit some kind of indecency, violence, or desecration.

On the other hand, this conclusion does not do justice to the constitutive role that social relations play in the formation of human identity and flourishing. As Eva Kittay articulates, it is in "a matrix of relationships embedded in social practices" that duties to each other are delineated and "emotional responses are deemed appropriate" (or inappropriate) [56, p. 111]. A brain-dead child is still someone's child, is still a part of a family with members who have special roles and duties in relation to this particular child. Moreover, flourishing generally happens to individuals insofar as they are emmeshed in the lives of other people who are also flourishing. Therefore, I think it is conceivable that a child like Jahi McMath-brain dead but not in perceivable pain, loved and cared for by her family [8]— did not suffer, but rather flourished unto death. ${ }^{21}$

\footnotetext{
20 This is similar to when PICU staff claim that a very sick patient with a very poor prognosis is suffering even when he is asleep or completely sedated. At least judging by ordinary language use and sensibilities, patients' suffering does not turn on and off like a light switch with their sleep cycles or when a large dose of sedatives is given. I believe this intuition supports the idea that suffering is not a feeling (at least for very sick pediatric patients); it is a state of affairs.

21 One reason, it seems, that an analysis of a brain-dead child's suffering is challenging is because it is unclear what the metaphysical status of a brain-dead person even is; it is difficult to assess a creature's flourishing, and therefore its suffering, if one is still unclear about what exactly it $i$.
} 


\section{Conclusions}

The aim of this paper was to explore and clarify the nature of pediatric suffering. To do so, I first examined two common ways that the label of suffering is used in pediatric medicine. Pediatric suffering is typically seen as either a mirage or a scandal. As the former, a child requires consciousness and cognition to have the capacity to suffer. As the latter, suffering is felt to be so heinous that it must be extinguished. I argued that both of these views are confused and fail to account for any particular child, or for what a child actually is.

In place of such construals, I advanced a view of pediatric suffering that identifies child suffering as the absence of child flourishing. For children, especially newborns and children with cognitive disability, suffering is located at one end of a suffering-flourishing spectrum. Suffering is therefore dislodged from its status as an essentially subjective and experiential phenomenon. Like flourishing, child suffering is a collective, social, political, and cultural event. Consequently, the prevention of child suffering takes a village.

My hope for this essay is that it will encourage clinicians and ethicists, like myself, to discipline our language. Suffering carries with it a rhetorically potent "gestalt quality" [4, p. 20], and misplaced descriptions of suffering can be a matter of life and death for children and of hope and grief for families. However, learning to describe the world accurately is critical, for to speak and act morally you must first know what you are talking about. I believe Stanley Hauerwas is correct when he asserts that "morally speaking, the first issue is never what we are to do, but what we should see. Here is the way it works: you can act only in the world that you can see, and you must be taught to see by learning to say" [57, p. 611]. Learning how to speak truthfully about suffering is therefore the task at hand.

Acknowledgments I would like to thank David Tate, Devan Stahl, Jeremy Millington, and the editors of Theoretical Medicine and Bioethics for their generous and constructive feedback on various stages of this paper. Notably, portions of this paper were presented at the 2019 Conference on Medicine in Religion in Durham, NC, USA and the 2019 Seattle Children's Pediatric Bioethics Conference in Seattle, WA, USA.

\section{References}

1. Hauerwas, Stanley. 1986. Suffering presence: Theological reflections on medicine, the mentally handicapped, and the Church. Notre Dame: University of Notre Dame Press.

2. Tate, Tyler. 2020. Philosophical investigations into the essence of pediatric suffering. Theoretical Medicine and Bioethics 41. https://doi.org/10.1007/s11017-020-09531-y.

3. Tate, Tyler. 2020. Pediatric suffering and the burden of proof. Pediatrics 146: S70-S74.

4. Salter, Erica K. 2020. The new futility? The rhetoric and role of "suffering" in pediatric decisionmaking. Nursing Ethics 27: 16-27.

5. Cassell, Eric J. 2013. The nature of healing: The modern practice of medicine. New York: Oxford University Press.

6. Sacks, Oliver. 1984. A leg to stand on. New York: Simon and Schuster.

7. Miller, Kathryn E., Ryan D. Coleman, Leah Eisenberg, Joan Henriksen, John D. Lantos, and Elliott Mark Weiss. 2018. Unilateral withdrawal of life-sustaining therapy in a severely impaired child. Pediatrics 142(5): e20180131. https://doi.org/10.1542/peds.2018-0131. 
8. Aviv, Rachel. 2018. What does it mean to die? New Yorker, February 5, 2018. https://www.newyo rker.com/magazine/2018/02/05/what-does-it-mean-to-die.

9. Verhagen, Eduard, and Pieter J.J. Sauer. 2005. The Groningen Protocol—euthanasia in severely ill newborns. New England Journal of Medicine 352: 959-962.

10. Brouwer, Marije, Christopher Kaczor, Margaret P. Battin, Els Maeckelberghe, John D. Lantos, and Eduard Verhagen. 2018. Should pediatric euthanasia be legalized? Pediatrics 141(2): e20171343. https://doi.org/10.1542/peds.2017-1343.

11. Blume, Elizabeth D., Emily Morell Balkin, Ranjit Aiyagari, Sonja Ziniel, Dorothy M. Beke, Ravi Thiagarajan, Laura Taylor, Thomas Kulik, Kenneth Pituch, and Joanne Wolfe. 2014. Parental perspectives on suffering and quality of life at end-of-life in children with advanced heart disease: An exploratory study. Pediatric Critical Care Medicine 15: 336-342.

12. Clément de Cléty, Stéphan, Marie Friedel, A.A. Eduard Verhagen, John D. Lantos, and Brian S. Carter. 2016. Please do whatever it takes to end our daughter's suffering! Pediatrics 137(1): e20153812. https://doi.org/10.1542/peds.2015-3812.

13. Suttle, Markita L., Tammara L. Jenkins, and Robert F. Tamburro. 2017. End-of-life and bereavement care in pediatric intensive care units. Pediatric Clinics of North America 64: 1167-1183.

14. Friedrich, Annie B., Kirsten M. Dempsey, and Erika K. Salter. 2019. The use of suffering in pediatric bioethics and clinical literature: A qualitative content analysis. Pediatric Ethicscope 32(2). https://pediatricethicscope.org/article/the-use-of-suffering-in-pediatric-bioethics-and-clini cal-literature-a-qualitative-content-analysis.

15. Cassell, Eric J. 2004. The nature of suffering and the goals of medicine, 2nd ed. New York: Oxford University Press.

16. Mayerfeld, Jamie. 1999. Suffering and moral responsibility. New York: Oxford University Press.

17. Brady, Michael. 2018. Suffering and virtue. Oxford: Oxford University Press.

18. Svenaeus, Fredrik. 2014. The phenomenology of suffering in medicine and bioethics. Theoretical Medicine and Bioethics 35: 407-420.

19. DeGrazia, David. 2014. What is suffering and what sorts of beings can suffer? In Suffering and bioethics, ed. Ronald M. Green and Nathan J. Palpant, 134-156. New York: Oxford University Press.

20. DeGrazia, David, and Andrew Rowan. 1991. Pain, suffering, and anxiety in animals and humans. Theoretical Medicine 12: 193-211.

21. Copp, Laurel Archer. 1974. The spectrum of suffering. American Journal of Nursing 74: 491-495.

22. Edwards, S.D. 2001. Prevention of disability on grounds of suffering. Journal of Medical Ethics 27: 380-382.

23. Davies, James. 2012. The importance of suffering: The value and meaning of emotional discontent. London: Routledge.

24. Stump, Eleonore. 2010. Wandering in darkness: Narrative and the problem of suffering. Oxford: Oxford University Press.

25. Tate, Tyler, and Robert Pearlman. 2019. What we mean when we talk about suffering — and why Eric Cassell should not have the last word. Perspectives in Biology and Medicine 62(1): 95-110.

26. van Hooft, Stan. 1998. Suffering and the goals of medicine. Medicine, Health Care and Philosophy 1: 125-131.

27. Herman, Judith. 2015. Trauma and recovery: The aftermath of violence-from domestic abuse to political terror. New York: Basic Books.

28. van der Kolk, Bessel A. 2015. The body keeps the score: Brain, mind, and body in the healing of trauma. New York: Penguin Books.

29. Brooten, Dorothy, JoAnne M. Youngblut, Carmen Caicedo, Lynn Seagrave, G. Patricia Cantwell, and Balagangadhar Totapally. 2016. Cause of death of infants and children in the intensive care unit: Parents' recall vs chart review. American Journal of Critical Care 25: 235-242.

30. Waldman, Elisha. 2018. Children, fatal illness and the nature of suffering. Scientific American (blog), May 25, 2018. https://blogs.scientificamerican.com/observations/children-fatal-illness-andthe-nature-of-suffering. Accessed July 11, 2020.

31. Wolfe, Joanne, Jim F. Hammel, Kelly E. Edwards, Janet Duncan, Michael Comeau, Joanna Breyer, Sarah A. Aldridge, Holcombe E. Grier, Charles Berde, Veronica Dussel, and Jane C. Weeks. 2008. Easing of suffering in children with cancer at the end of life: Is care changing? Journal of Clinical Oncology 26: 1717-1723.

32. Salinger, J.D. 1961. Franny and Zooey. Boston: Little, Brown. 
33. Brady, Michael S. 2019. Emotion: The basics. Abingdon: Routledge.

34. Streri, Arlette, Maria Dolores De Hevia, Véronique Izard, and Aurélie Coubart. 2013. What do we know about neonatal cognition? Behavioral Sciences 3: 154-169.

35. Tomasello, Michael. 2019. Becoming human: A theory of ontogeny. Cambridge: Harvard University Press.

36. Lewis, C.S. 1960. The four loves. New York: Harcourt Brace.

37. Kuhl, Patricia K., Feng-Ming Tsao, and Huei-Mei Liu. 2003. Foreign-language experience in infancy: Effects of short-term exposure and social interaction on phonetic learning. Proceedings of the National Academy of Sciences 100: 9096-9101.

38. Gumperz, John J. 1982. Discourse strategies. Cambridge: Cambridge University Press.

39. MacIntyre, Alasdair. 1999. Dependent rational animals: Why human beings need the virtues. Chicago: Open Court.

40. Boorse, Christopher. 2014. A second rebuttal on health. Journal of Medicine and Philosophy 39: 683-724.

41. Boorse, Christopher. 1977. Health as a theoretical concept. Philosophy of Science 44: 542-573.

42. Engelhardt, H. Tristram, Jr. 1996. The foundations of bioethics, 2nd ed. New York: Oxford University Press.

43. Nussbaum, Martha C. 1992. Human functioning and social justice: In defense of Aristotelian essentialism. Political Theory 20: 202-246.

44. Foot, Philippa. 2001. Natural goodness. Oxford: Oxford University Press.

45. Wilkinson, Dominic, and Amir Zayegh. 2020. Valuing life and evaluating suffering in infants with life-limiting illness. Theoretical Medicine and Bioethics 41. https://doi.org/10.1007/s11017-02009532-x.

46. Nussbaum, Martha C. 2006. Frontiers of justice: Disability, nationality, species membership. Cambridge: Harvard University Press.

47. Hauerwas, Stanley. 1977. Must a patient be a person to be a patient? Or, my uncle Charlie is not much of a person but he is still my uncle Charlie. In Truthfulness and tragedy: Further investigations in Christian ethics, 127-131. Notre Dame: University of Notre Dame Press.

48. Chappell, Timothy. 2011. On the very idea of criteria for personhood. Southern Journal of Philosophy 49: 1-27.

49. Campelia, Georgina D., Jennifer C. Kett, and Aaron Wightman. 2020. Relational suffering and the moral authority of love and care. Theoretical Medicine and Bioethics 41. https://doi.org/10.1007/ s11017-020-09530-z.

50. Mumford, James. 2013. Ethics at the beginning of life: A phenomenological critique. Oxford: Oxford University Press.

51. Garland-Thomson, Rosemarie. 2012. The case for conserving disability. Journal of Bioethical Inquiry 9: 339-355.

52. McMahan, Jeff. 1996. Cognitive disability, misfortune, and justice. Philosophy and Public Affairs 25: 3-35.

53. Francis, Neil. 2016. Neonatal deaths under Dutch Groningen Protocol very rare despite misinformation contagion. Journal of Assisted Dying 1: 7-19.

54. Verhagen, A.A. Eduard, Jozef H.H.M. Dorscheidt, Bernadette Engels, Joep H. Hubben, and Pieter J. Sauer. 2009. End-of-life decisions in Dutch neonatal intensive care units. Archives of Pediatrics and Adolescent Medicine 163: 895-901.

55. van Hooft, Stan. 1998. The meanings of suffering. Hastings Center Report 28(5): 13-19.

56. Kittay, Eva Feder. 2005. At the margins of moral personhood. Ethics 116: 100-131.

57. Hauerwas, Stanley. 2001. Abortion, theologically understood. In The Hauerwas reader, ed. John Berkman and Michael Cartwright, 603-622. Durham, NC: Duke University Press.

Publisher's Note Springer Nature remains neutral with regard to jurisdictional claims in published maps and institutional affiliations. 